O Sistema Nacional de Educação, previsto na Constituição Federal de 1988 (Artigo 214), deve ser instituído no prazo de dois anos, contados a partir da publicação da Lei 13.005/2014 (Artigo 13). O texto abaixo foi

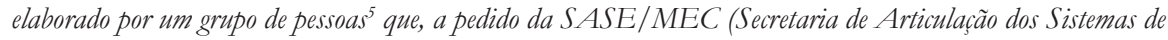
Ensino) se dispôs a propor os primeiros acordos em linhas gerais sobre o tema, buscando estimular o discussões em todo o país para a construcão de uma proposta coletiva que encontre eco no Congresso Nacional. Portanto, a agenda instituinte já está em curso..

Brasilia, julbo de 2014

\title{
O SISTEMA NACIONAL DE EDUCAÇÃO
}

O Brasil é uma República Federativa formada pela união indissolúvel dos Estados e Municípios e Distrito Federal ${ }^{6}$, com autonomia dos entes membros da União e o resguardo de competências que lhes são próprias. Ao se estruturar como tal, a Constituição o fez sob o princípio da cooperação entre os entes federativos, consoante o Parágrafo Único do Artigo 23, e do Regime de Colaboração entre os sistemas de ensino, conforme o Artigo 211.

Assim, a Constituição expressa a escolha por um regime normativo e político, plural e descentralizado em que se cruzam mecanismos de participação social com um modelo cooperativo e colaborativo que ampliou o universo de sujeitos capazes de participar das decisões. Por isso mesmo a cooperação supõe o entendimento entre os entes federativos; a colaboração exige a harmonia entre os sistemas e admite novas arenas de participação advindas da sociedade civil.

Muitos avanços foram alcançados nas últimas décadas em termos de construção de acordos federativos para a garantia dos direitos constitucionais. $\mathrm{Na}$ política educacional o país registra significativa ampliação do acesso e melhoria na qualidade do serviço público ofertado, resultantes das alterações legais, de novos marcos no financiamento, qualificação da gestão e do compromisso social de expressiva parcela da sociedade.

Porém existem fragilidades importantes a serem ainda superadas, em decorrência de limites dos padrões nacionalmente pactuados e das lacunas nas normas de cooperação federativa para o exercício das competências da União, Estados, Distrito Federal e Municípios. Aliadas a estes fatores apresentam-se como pano de fundo as históricas desigualdades econômicas e sociais no Brasil, que potencializam a complexidade e as tensões próprias do contexto federativo e que dificultam a organização da educação brasileira com formas de colaboração capazes de efetivamente garantir o direito constitucional. Descontinuidade de

\footnotetext{
5 Carlos Augusto Abicalil; Carlos Roberto Jamil Cury; Luiz Fernandes Dourado e Romualdo Portela (convidados externos); Maria Beatriz Luce, Binho Marques e Flávia Nogueira (Ministério da Educação) 
ações, fragmentação de programas, falta de articulação entre órgãos gestores e carência de recursos são situações especialmente visíveis.

No campo dos muitos avanços conquistados está a Emenda Constitucional 59/2009, um dispositivo que fortalece o direito à educação como um direito próprio da democracia e oferece ao federalismo cooperativo, signo da República, uma nova condição: o Plano Nacional de Educação (PNE) como articulador do Sistema Nacional de Educação (SNE). O caráter novo e original deste dispositivo aponta para uma ampliação do direito à educação como dever do Estado: olha para trás, para o presente e para o futuro. Para trás, no sentido de reduzir as assimetrias educacionais ainda existentes, em vista da equalização de oportunidades para todos em matéria de educação escolar ${ }^{1}$ e das desigualdades sociais e regionais ${ }^{2}$. Ao mesmo tempo, indica a garantia do padrão de qualidade ${ }^{3}$ para o presente, olhando para o futuro por meio do PNE, Lei 13.005/14.

O que se infere deste dispositivo é que o Sistema Nacional de Educação já existe pela sua inserção no corpo constitucional. Assim, o Sistema Nacional de Educação já é. Mas... eis ainda a questão: em que ele consiste? Um sistema - entende-se - é um conjunto articulado e coordenado de elementos coexistentes e que, dentro de um determinado espaço e tempo, compartilham de um mesmo ordenamento estruturado. No caso de um Sistema Nacional de Educação, tal contexto remete à definição de diretrizes, metas, recursos e estratégias de manutenção e desenvolvimento direcionadas à garantia do direito social à educação em ambos os níveis (educação básica e superior), considerando todas as etapas e modalidades educativas. Remete, sobretudo, à garantia da universalização da educação básica obrigatória dos 04 aos 17 anos, em regime de colaboração.

O país chegou aos dias atuais, portanto, com a meta de instituir o Sistema em dois anos, que começaram a ser contados a partir da publicação da Lei do novo PNE, segundo seu Artigo 13. Este será um enorme desafio. Para tanto, as funções de coordenação e de articulação do Estado Nacional ${ }^{4}$, em seu movimento conjunto de conexão entre os vários entes, só se realizam caso haja um foro formulador a fim de se obter uma sincronia interna, evitando-se antinomias entre os sistemas. Este foro é a União, que tem no Ministério da Educação seu órgão de coordenação e, em um renovado Conselho Nacional, o seu eixo normativo. Este foro, dentro do Estado Democrático de Direito e Republicano, não é o centro de um poder hierárquico. Ao contrário, ele é um lugar em que os vários poderes

1 em consonância com o Artigo 211, Parágrafo 1o.

$2 \quad$ Artigo $^{\circ}$, Inciso III e Artigo 43.

3 prevista no Artigo 206, Inciso VII, da Constituição Federal.

$4 \quad$ Artigo $8^{\circ}$, Parágrafo $1^{\circ}$ da LDB. 
autônomos pactuam uma descentralização qualificada pela ação coordenada própria do regime de colaboração ${ }^{5}$.

No complexo cenário das esferas públicas administrativas autônomas, dispostas de forma não hierárquica, a CONAE 2010 apontou para a necessária regulamentação do Artigo 23 da Constituição Federal de 1988, que, por meio de Lei Complementar, deve definir competências comuns à União, aos Estados, ao Distrito Federal e aos Municípios, estando, entre elas, a tarefa de proporcionar os meios de acesso à educação.

Entretanto, a pactuação federativa a ser expressa e concretizada em Lei Complementar que regulamente tal Artigo, por si só, não configurará o Sistema. As perguntas que antecedem a regulamentação são: qual é a finalidade do Sistema e qual é o projeto nacional que dirigirá a elaboração das normas de cooperação?

O sentido para a existência de um Sistema, por intermédio de uma nova forma de organização, é a garantia do direito de acesso e qualidade a educação a todos os brasileiros, com padrões nacionais e políticas capazes de levar o país a superar as desigualdades históricas no campo educacional.

A educação no Brasil é nacional porque se assenta em diretrizes e bases ${ }^{6}$, que cobrem o conjunto dos sistemas de ensino (o federal, os estaduais, o distrital e os municipais e, no seu interior, as redes públicas e privadas que os constituem). Portanto, será imprescindível uma releitura da LDB à luz do Sistema Nacional de Educação a ser configurado.

A adoção dos padrões nacionais vinculantes por todos os sistemas de ensino será basilar para o SNE, pois trata-se de garantir um direito juridicamente protegido assegurando cidadania e direitos humanos. Dentre os elementos que conformarão a identidade nacional, estão: uma base nacional comum para os currículos da educação básica e superior, financiamento adequado, padrões para as instituições educativas, gestão democrática, formação e valorização dos profissionais, com carreiras elaboradas a partir de parâmetros nacionais e que tomem como referência a Lei 11.738/08 (que institui o Piso Salarial Profissional Nacional para os profissionais do magistério público da educação básica), processos de avaliação institucional e de aprendizagem, entre outros.

Este reexame da LDB realçará a natureza de um SNE e a regulamentação do Artigo 23 concretizará normas de cooperação também vinculantes, capazes de dar sustentação ao projeto que se desenhou. Em ambos os casos (regulamentação do Artigo 23 e reexame da LDB) é imprescindível reforçar os papeis de coordenação política, suplementação e redistribuição da União com relação aos

\footnotetext{
$5 \quad$ Artigo $7^{\circ}$ da Lei $13.005 / 2014$.

6 Inciso XXIV do Artigo 22 da Constituição Federal.
} 
Estados e Municípios e também dos Estados com relação aos seus próprios Municípios.

O papel de cada ente federativo deverá ser conformado e potencializado por um conjunto de responsabilidades e corresponsabilidades muito claramente definidas. Da autonomia e das competências atribuídas deve resultar também, decorrente do dever de Estado, o esforço endógeno e institucional dos Estadosmembros para a criação de seus sistemas em regime de colaboração e em total coerência ao Sistema Nacional de Educação ${ }^{7}$. Neste contexto, a interdependência é um conceito indispensável para que se possa construir processos de descentralização qualificada, isto é, de repartição de competências acompanhadas das condições necessárias para sua efetivação.

Com a definição de normas de cooperação, padrões nacionais de qualidade $^{8}$ e capacidade de atendimento, todos os brasileiros terão seu direito assegurado em qualquer ponto do território nacional. O equilíbrio entre estes elementos, à vista da diferenciada capacidade de cada unidade federativa e dos fundos públicos disponíveis, deverá contar com condições de supletividade para que as esferas de governo garantam que seus sistemas atuem de forma colaborativa, interdependente e equitativa.

A função supletiva é um meio pelo qual a União, à vista de uma incapacidade justificada de o ente federado dar conta de um padrão mínimo de qualidade, subsidia, provisoriamente, aquele ente em termos financeiros? ${ }^{9}$ O mesmo se pode dizer do Estado em relação ao Município, considerada a real situação de cada qual.

Em face das assimetrias existentes, a ação supletiva implica a equidade ${ }^{10}$ como uma decorrência da justiça. A aparente antinomia com relação à igualdade perante a lei, se resolve mediante o estabelecimento de objetivos e metas claros a serem conseguidos na superação das desigualdades, disparidades e discriminações por meio de apoio financeiro e técnico, em que se resguarde a destinação pertinente. As desigualdades sociais, disparidades regionais e discriminações culturais, por enunciado, atingem as pessoas, as regiões e os grupos socialmente desfavorecidos. E estes são os campos da equidade perante os quais cabe à União

\footnotetext{
$7 \quad$ Artigo 211 da Constituição Federal.

8 Padrão mínimo de qualidade: Artigo 211, parágrafo 1o e Artigo 75 da LDB; Padrão de qualidade: Artigo 206 CF 88, inciso 7 e Artigo 30 da LDB, inciso 9.

9 A função supletiva também pode ser do direito, significando o estabelecimento de uma norma quando, em face de casos concretos, tem-se a carência de uma regra específica.

10 Segundo os clássicos, a equidade é um conceito que cobre a realização da igualdade de direitos quando esta última se revela insuficiente para propiciar oportunidades iguais para todos. Esta realização, baseada no "tratar desigualmente os desiguais" necessita de um apoio jurídico procedimental para tal. É o que temos no parágrafo 1 o da CF 88 e nos Artigos 75 e 76 da LDB, afora a exigência do Artigo 3o da CF 88.
} 
e aos Estados, o esforço da função supletiva. Tratar, pois, desigualmente os desiguais na medida da desigualdade aponta para uma alteridade desigual a fim de se alcançar patamares novos e sucessivos de igualdade.

Quanto ao papel redistributivo, o FUNDEF e o FUNDEB representaram avanços muito significativos, mas o modelo carece de aperfeiçoamento no sentido de vincular o custo anual do aluno a um padrão de qualidade nacionalmente pactuado que oriente a função supletiva. Neste cenário, o SNE, longamente postulado por educadores e gestores, torna-se condição para o aprofundamento de um autêntico regime de colaboração e aplicação de recursos (recursos novos inclusive), pelo inciso VI do Artigo 214, dentro de um ansiado Plano Nacional de Educação. Regras de financiamento aperfeiçoadas deverão considerar, também, a efetiva complementação da União para o cumprimento do Piso Salarial Profissional Nacional em todo o país, condição básica para a valorização dos educadores brasileiros.

Como as condições de supletividade são dinâmicas e diferentes para cada unidade federativa, serão imprescindíveis espaços tri e bipartites de pactuação, respectivamente, no nível nacional e nos Estados, segundo a Lei 13.005/2014, Artigo 7o. A mediação entre a necessidade de promoção dos direitos e a capacidade de oferta no âmbito de um Sistema Nacional de Educação, compreendido como um Sistema de Sistemas Estaduais, Distrital e Municipais, depende de um consistente e permanente debate na sociedade. As Conferências Nacionais da Educação (CONAE) e o Fórum Nacional de Educação (FNE), que as organiza, são importantes referências do exercício da democracia e devem ser apropriados como parte integrante do SNE a ser instituído.

Por tudo o que foi dito, a consistência de um Sistema Nacional de Educação decorrerá do direito à educação e do dever do Estado efetivados, seja naquilo que é nacional, seja no que é próprio do regime autonômico federativo, inclusive no respeito às diversidades culturais. A presença dos adjetivos comum, básico e mínimo na Constituição e na Lei de Diretrizes e Bases da Educação Nacional colabora, do ponto de vista conceitual e da legislação, para a articulação entre o nacional e o local. Este comum, básico e mínimo, de um lado, evitam a dispersão e, de outro, efetivam a articulação do uno e do múltiplo por meio de uma ação organizada e permanente do Estado Nacional.

A organização de um sistema educacional é a busca de uma organização pedagógica de caráter nacional, respeitados os princípios do federalismo. Porém, cada vez que esse assunto foi pautado em Constituintes, Leis de Diretrizes e Bases, Planos Nacionais de Educação e fundos de financiamento, ele foi motivo de intensos debates polêmicos, sobretudo quando o adjetivo nacional entrou em pauta. 
Seu não acolhimento se deveu a várias justificativas. Havia um temor de invasão indébita na autonomia dos entes federativos e, com isto, a eventual perda de autonomia dos mesmos. Após 164 anos de descentralização, havia o medo de uma centralização por parte do Estado Federal enquanto Estado Nacional. Havia o receio, por parte do segmento privado na educação escolar, de se ferir a liberdade de ensino e não faltava quem assinalasse o perigo do monopólio estatal. E havia também medo da parte da própria União quanto a uma presença mais efetiva, sobretudo no que se refere ao financiamento da educação básica.

Em que pese os avanços conquistados na educação escolar, o processo de produção da desigualdade, de cujo peso a realidade atual ainda é reveladora, vai mostrando a face dos sujeitos da privação: negros, pardos, migrantes do campo e de regiões mais pobres do país, trabalhadores manuais, moradores de bairros periféricos e pessoas fora da faixa etária legal. As resistência tácitas e explícitas contra a assinalação de um Sistema Nacional de Educação, seja por entidades privadas, seja por Estados-membros da Federação, seja pela própria União, fazem parte do complexo cenário de elaboração e pactuação, próprios do federalismo brasileiro $^{11}$.

Superadas tais resistências quanto à presença do dispositivo em sede constitucional, ou mesmo pela sua recepção no ordenamento infraconstitucional, este desfecho na história aponta para a necessidade de explicitar um novo e inédito conceito, inclusive para vê-lo em movimento na educação nacional. A grande tarefa nacional e desafio histórico é dar consistência ao SNE para a garantia do direito constitucional. 